\title{
Reducing Sugar-Producing Bacteria from Guts of Tenebrio Molitor Linnaeus (Yellow mealworm) for Lignocellulosic Waste Minimization
}

\author{
WEI QI ${ }^{1}$, CHIA-LUNG CHEN ${ }^{2}$, and JING-YUAN WANG ${ }^{1,2 *}$ \\ ${ }^{1}$ School of Civil and Environmental Engineering, Nanyang Technological University, 50 Nanyang Avenue, Singapore \\ 639798; and ${ }^{2}$ Residues and Resource Reclamation Centre (R3C), Nanyang Technological University, 50 Nanyang \\ Avenue, Singapore 639798
}

(Received April 10, 2011—Accepted July 9, 2011—Published online August 24, 2011)

The guts of Tenebrio Molitor Linnaeus (yellow mealworm) were used as inocula to isolate reducing sugar-producing bacteria during bioconversion of lignocellulose to reducing sugars in this study. Three carbon sources, i.e., carboxymethyl cellulose (CMC), filter paper (FP), and lignocellulosic waste (LIG), were specifically selected; and two types of culturing media (M1 and M2) were used. After 6 months of sequential cultivation, lignocellulose (i.e., polysaccharides) degradation of enrichments M1-CMC (47.5\%), M1-FP (73.3\%), M1-LIG (70.4\%), M2-CMC (55.7\%), M2-FP (73.1\%) and M2-LIG (71.7\%) was achieved, respectively, with incubation for $48 \mathrm{~h}$. Furthermore, seven bacterial strains were successfully isolated corresponding to most of the major bands detected by denaturing gradient gel electrophoresis analysis. The maximum reducing sugars yield by the combination of Agromyces sp. C42 and Stenotrophomonas sp. $\mathrm{A} 10 \mathrm{~b}$ was $56.7 \mathrm{mg} \mathrm{g} \cdot \mathrm{LIG}^{-1}$ of $48 \mathrm{~h}$, which is approximate $2-5$ times higher than the original enrichments and individual microbial strains. These findings suggest that bioconversion by microorganisms from mealworm guts has great application potential for lignocellulose hydrolysis.

Key words: mealworm guts, reducing sugars-producing bacteria, microbial hydrolysis, lignocellulosic waste

Chemical, mechanical, and enzymatic approaches have been used in the hydrolysis of lignocellulose (i.e., consisting of cellulose, hemicellulose and lignin) to release primarily hexose and pentose sugars for subsequent fermentation to ethanol, lactic acid and xylitol $(19,23)$; however, some drawbacks of these conventional approaches (e.g., inhibition by acid of the subsequent bioprocess, and the high cost of the enzyme) $(7,17,22,25)$ have attracted the attention of scientists. Alternatively, recent studies on microbial degradation of large molecules, such as cellulose, hemicellulose, and lignin, have suggested that bioconversion is a possible treatment of lignocellulosic waste $(3,9,11)$.

Ruminant animals have been reported to utilize cellulose as an energy source, depending on a symbiotic relationship with microbes in the rumen $(15,18)$. Mealworms are known as the primary consumers of organic residues. The ingestion and digestion of organic residues by mealworms trigger a series of physiological and biochemical events that result in the conversion of protein, carbohydrate and lipid into utilizable nutrients (27). Although insect digestion has been studied for more than a century, current understanding of this subject is far from complete.

Mealworm gut microbes have been studied on digestive enzymes such as cellobiase, cellulase and amylase $(5,26)$. Efficient microbial strains from mealworm guts for lignocellulosic waste degradation under aerobic conditions and the production of reducing sugars remain to be further explored. In the present study, microorganisms in the guts of Tenebrio Molitor Linnaeus (yellow mealworm) were selected as the species has been reported to survive on a diet of lignocellulose

\footnotetext{
* Corresponding author. E-mail: jywang@ntu.edu.sg;

Tel.: +65-6790-4100; Fax: +65-67927319.
}

biomass powder for at least 15 days. Three sole-carbon sources, i.e., carboxymethyl cellulose (CMC), filter paper (FP) and lignocellulosic waste (LIG), were used to enrich lignocellulose-degrading bacteria. Both culture-independent and culture-dependent approaches were engaged to characterize lignocellulose-degrading microbial isolates. A microbial cocktail was also investigated to further promote reducing sugar yield from lignocellulosic materials because a mixed culture with "symbiosis activity" might promote lignocellulose degradation $(10,12)$.

Lignocellulosic waste is one of the sustainable sources in nature compared with food-based feedstock for fuel ethanol production. The findings of this study are expected to extend our understanding of reducing sugar-producing microorganisms from guts, and to provide a basis for developing optimal control and management strategies for the treatment of lignocellulosic waste in the future.

\section{Materials and Methods}

\section{Sample collection and batch enrichment}

Tenebrio Molitor Linnaeus (yellow mealworm) was our laboratory stock and was fed with lignocellulosic waste for 2 weeks prior to use. These mealworms were surface sterilized by $70 \%$ ethanol and subsequently washed in sterilized water. Every 8 mealworms were disrupted by passing through a syringe needle for each medium (described below). The disrupted gut debris were suspended in 200 $\mathrm{mL}$ medium 1 (i.e., yeast extract, $0.04 \mathrm{~g} \mathrm{~L}^{-1}$; malt extract, $100 \mathrm{mg}$ $\mathrm{L}^{-1} ; \mathrm{CaCO}_{3}, 2.0 \mathrm{~g} \mathrm{~L}^{-1} ; \mathrm{pH}$ 7.0 \pm 0.2 ) (30) and medium 2 (i.e., $\left[\mathrm{NH}_{4}\right]_{2} \mathrm{SO}_{4}, 2.0 \mathrm{~g} \mathrm{~L}^{-1} ; \mathrm{CaCl}_{2}, 0.1 \mathrm{~g} \mathrm{~L}^{-1} ; \mathrm{KH}_{2} \mathrm{PO}_{4}, 0.5 \mathrm{~g} \mathrm{~L}^{-1} ; \mathrm{K}_{2} \mathrm{HPO}_{4}$, $2.0 \mathrm{~g} \mathrm{~L}^{-1} ; \mathrm{MgSO}_{4} \cdot 7 \mathrm{H}_{2} \mathrm{O}, 0.1 \mathrm{~g} \mathrm{~L}^{-1} ; \mathrm{NaCl}, 6.0 \mathrm{~g} \mathrm{~L}^{-1}$; yeast extract, $1.0 \mathrm{~g} \mathrm{~L}^{-1}$ ), respectively. Both medium 1 and medium 2 were supplemented with carboxymethyl cellulose (CMC; $10 \mathrm{~g} \mathrm{~L}^{-1}$; Fluka, Buchs, Switzerland; degree of substitution 0.70-0.85; M1-CMC and M2-CMC), filter paper strips (FP; $10 \mathrm{~g} \mathrm{~L}^{-1}$; M1-FP and M2-FP), 
and lignocellulose waste powder (LIG; $10 \mathrm{~g} \mathrm{~L}^{-1} ;<1 \mathrm{~mm}$; M1-LIG and M2-LIG), respectively.

Each $250 \mathrm{~mL}$ Erlenmeyer flask was loaded with the crushed guts of 8 mealworms as inocula in 2 basic nutrients with three carbon sources, respectively. The culture medium was adjusted to $\mathrm{pH}$ $7.0 \pm 0.2$. The flasks were placed in a reciprocal incubation shaker (OLS 200, Grant Instruments, Cambridge, UK) with a horizontal rotation speed of $150 \mathrm{rpm}$ at $30 \pm 2^{\circ} \mathrm{C}$. For the first batch, $50 \%$ (v/ v) of cultivated solution (including the used medium, cultures, and carbon source) was removed after 15-day incubation, and replaced with $100 \mathrm{~mL}$ fresh sterilized medium and $10 \mathrm{~g}$ of each sterilized carbon source. After the third batch, $75 \%(\mathrm{v} / \mathrm{v})$ of the cultivated solution was removed and supplemented with $150 \mathrm{~mL}$ fresh sterilized medium and $10 \mathrm{~g}$ of each sterilized carbon source. Polysaccharide degradation and reducing sugar yield were monitored 1-2 times a week. This enrichment process was conducted for up to 6 months. Subsequently, batch degradation assays and microbial community analyses were carried out with effective lignocellulose-degrading microbial combinations. For batch degradation tests, polysaccharide degradation and reducing sugar production were measured at the end of $24 \mathrm{~h}$ and $48 \mathrm{~h}$ incubation and continuously monitored for $7 \mathrm{~d}$.

\section{Preparation of lignocellulose}

Lignocellulosic waste was obtained from a local landscaping and construction firm in Singapore. The main components of raw waste are leaves, uprooted weeds, twigs, grass clippings and small branches. Raw waste was washed thoroughly with water to remove soil and clay, and was subsequently milled to powder of $<1 \mathrm{~mm}$. Extracts (e.g., waxes, fats, some resins and portions of wood gums) were removed to liberate cellulose and hemicellulose from lignin with toluene-ethanol $(2: 1, \mathrm{v} / \mathrm{v})$ in a Soxhlet apparatus (Schott, Mainz, Duran, Germany) for $6 \mathrm{~h}$ and were heated at $60^{\circ} \mathrm{C}$ until completely dry (24)

\section{Chemical analyses}

A phenol-sulfuric acid method was used to quantify polysaccharides (4), with glucose as the standard. Polysaccharide degradation efficiency (\%) was calculated by dividing the difference of initial and remaining (each day) polysaccharide concentration to initial polysaccharide concentration and multiplying by 100 . Monosaccharides were measured by the DNS method with glucose as the standard (14). Each sample was measured in triplicate. In addition, $\mathrm{pH}$ was measured with a PCD $6500 \mathrm{pH}$ meter (CyberScan, Eutech Instruments, Ayer Rajah Crescent, Singapore).

\section{Scanning electron microscopy (SEM)}

After a 6-month enrichment process, the microorganisms were gently washed with a phosphate buffer solution and fixed for 4 hours in $4 \%$ paraformaldehyde. The fixed samples were subsequently dehydrated through a series of ethanol solutions with increasing concentrations $(40,60,80$ and $100 \%)$ and dried with a Freeze Dryer (Edwards, Crawley, West Sussex, UK) or Critical Point 6 Dryer (E3000) (VG Microtech, East Grinstead, West Sussex, UK). The cell morphology was examined and observed by a scanning electron microscope (JSM-6400, JEOL, Tokyo) at an accelerating voltage of 12 or $15 \mathrm{kV}$.

\section{Isolation}

Nutrient agar (Difco, Becton Dickinson, Sparks, MD, USA) was used for bacterial isolation. The solution of each of the six enrichments (after 6 months of enrichment) was serially diluted with sterilized water $\left(10^{1}\right.$ to $10^{6}$-fold dilutions), and $0.1 \mathrm{~mL}$ of each dilution was spread onto agar plates. The plates were incubated in an incubator at $30^{\circ} \mathrm{C}$ until clear colonies appeared. After three successive transfers, distinct colonies had been further transferred to lignocellulose agar plates (with LIG powder as sole carbon source, $10 \mathrm{~g} \mathrm{~L}^{-1}$ ) to confirm that the isolated strains were able to utilize lignocellulose. Redundancy of the obtained microbial strains was eliminated based on colony morphology, color and size.

\section{Denaturing gradient gel electrophoresis (DGGE)}

After six months of enrichment, genomic DNA of six enrichments was extracted by a ZYMO research soil microbe DNA extraction kit (ZYR, Zymo Research, Irvine, CA, USA). The PCR-amplified fragments (primer set P2/P3-GC [16], corresponding to positions 341 and 534 in the Escherichia coli sequence) were separated by a DCode universal mutation detection system (Bio-Rad Laboratories, Hercules, CA, USA) under the conditions of $1 \times$ TAE buffer, $85 \mathrm{~V}$, at $60^{\circ} \mathrm{C}$ for $15 \mathrm{~h}$. Subsequently, the gel was stained with ethidium bromide and photographed with an EDAS 290 gel imaging system (Eastman Kodak Company, Rochester, NY, USA).

\section{Phylogenetic analyses}

The 16S rRNA gene of microbial isolates was amplified by the whole-cell direct-lysis PCR amplification method. The bacterial primer set $8 \mathrm{~F} / 1490 \mathrm{R}$ was used to amplify the approximate full length of the 16S rRNA gene for the isolates (29). Subsequently, the PCR products were purified with a Wizard SV Gel and PCR Clean-up System (Promega, Madison, WI, USA) according to the manufacturer's instructions and stored at $-20^{\circ} \mathrm{C}$ before sequencing by a local sequencing service company ( $1^{\text {st }}$ BASE, Science Park Road, Singapore).

The obtained sequences were compared to the sequences available from the Ribosomal Database Project (RDP) and the EMBL/ GenBank databases for phylogenetic analyses. The obtained relevant sequences were aligned using the Clustal W algorithm (program version 1.83), and a neighbor-joining tree was constructed with 100 bootstraps using the PHYLIP program package 3.9. Aquifex pyrophilus (M83548) was used as the outgroup.

\section{Microbial cocktail}

$180 \mathrm{~mL}$ culture medium (with $10 \mathrm{~g} \mathrm{~L}^{-1}$ of each pretreated carbon source) and $20 \mathrm{~mL}$ bacterial cell solution (with consistent cell concentration $\mathrm{OD}_{600}$ of $0.017 \pm 0.001$ ) using a spectrophotometer (DU 640 B, Beckman-Coulter, Fullerton, CA, USA) were prepared and mixed in a $250 \mathrm{~mL}$ Erlenmeyer flask. All cultures were carried out on a shaking incubator (Multitron, Infors AG, Bottmingen, Switzerland) at $30^{\circ} \mathrm{C}$ and with $120-150$ revolutions per minute (rpm). The concentration of reducing sugars was analyzed after $24 \mathrm{~h}, 48 \mathrm{~h}$ and continuously monitored for $7 \mathrm{~d}$.

\section{Accession numbers of nucleotide sequences}

Nucleotide sequences of the partial 16S rRNA genes of the isolated bacteria have been deposited in GenBank/EMBL/DDBJ under accession numbers GU394953 to GU394959.

\section{Results}

\section{Degradation properties of the microbial community}

Table 1 shows the performance of polysaccharide (i.e., cellulose and hemicellulose) degradation by the six enrichments (i.e., M1-CMC, M1-FP, M1-LIG, M2-CMC, M2-FP and M2-LIG) after 6-month successful enrichment processes. The initial polysaccharide concentration ranged from 3,683.9 to $4,279.9 \mathrm{mg} \mathrm{L}^{-1}$. Polysaccharide degradation was rapid in the initial $24 \mathrm{~h}(44.6 \%, 23.2 \%, 56.5 \%, 23.3 \% 45.8 \%$ and $71.7 \%$ for M1-CMC, M1-FP, M1-LIG, M2-CMC, M2-FP and M2-LIG respectively), and further increased at $48 \mathrm{~h}$ $(47.5 \%, 73.3 \%, 70.4 \%, 55.7 \%$ and $73.1 \%$ for M1-CMC, M1FP, M1-LIG, M2-CMC and M2-FP, respectively), except M2-LIG. No significant degradation of polysaccharides was observed after $48 \mathrm{~h}$.

Accompanying polysaccharide degradation, the reducing sugar yield increased significantly, ranging from 6.1 to 30.5 $\mathrm{mg}$ g-substrate ${ }^{-1}$ in the first $24 \mathrm{~h}$. Among them, the greatest 
Table 1. Polysaccharide degradation and reducing sugar production by microbial consortia

\begin{tabular}{|c|c|c|c|c|c|}
\hline \multirow[t]{2}{*}{ Substrates } & \multirow{2}{*}{$\begin{array}{l}\text { Initial } \\
\text { polysaccharide } \\
\text { concentration } \\
\left(\mathrm{mg} \mathrm{L}^{-1}\right)\end{array}$} & \multicolumn{2}{|c|}{$\begin{array}{c}\text { Polysaccharide } \\
\text { degradation } \\
\text { efficiency }(\%)\end{array}$} & \multicolumn{2}{|c|}{$\begin{array}{c}\text { Reducing sugar } \\
\text { production } \\
\left.\text { (mg g-substrate }^{-1}\right)\end{array}$} \\
\hline & & $24 \mathrm{~h}$ & $48 \mathrm{~h}$ & $24 \mathrm{~h}$ & $48 \mathrm{~h}$ \\
\hline & & $446+0$ & $47.5 \pm$ & $9.9 \pm$ & $10.5 \pm$ \\
\hline & 3,68 & $2 \pm 0.6$ & 73 & $6.1 \pm$ & \\
\hline & & $56.5 \pm 0.8$ & & $7.3 \pm 0.5$ & $7.5 \pm 0.7$ \\
\hline & & $23.3 \pm 0.8$ & $55.7 \pm 0$ & $30.5 \pm 2.2$ & $29.2 \pm 2.2$ \\
\hline & & $45.8 \pm 1.4$ & & $9.7 \pm 0.8$ & $9.3 \pm 0.6$ \\
\hline M2-LIG & $4,000.0 \pm 2.2$ & $71.7 \pm 1.0$ & $55.4 \pm 2.2$ & $12.4 \pm 1.3$ & $12.6 \pm 1.3$ \\
\hline
\end{tabular}

reducing sugar yield was observed in M2-CMC (30.5 mg gsubstrate $\left.^{-1}\right)$. The reducing sugar yield by M1-CMC, M1-FP, M1-LIG and M2-LIG slightly increased to 10.5, 6.5, 7.5 and $12.6 \mathrm{mg}_{\mathrm{g}-\mathrm{substrate}^{-1}}$ at $48 \mathrm{~h}$, respectively. In contrast, the reducing sugar yield by M2-CMC and M2-FP slightly decreased to 29.2 and $9.3 \mathrm{mg}$ g-substrate ${ }^{-1}$ at $48 \mathrm{~h}$. Additionally, the concentration of reducing sugars in the six enrichments decreased after $48 \mathrm{~h}$ (data not shown). In the degradation of polysaccharides, the production and consumption of reducing sugars occur simultaneously during cultivation, so observation of the decrease might be due to the faster consumption than production of reducing sugar by the bacteria in the combinations. The overall results indicated that the polysaccharides were degraded significantly within $48 \mathrm{~h}$ by these selected microbial communities, and reducing sugars were produced mainly in this period. This suggests the reducing sugars should be harvested in this period.

\section{SEM and DGGE observations}

Fig. 1 shows the microbial morphotypes presented in the six enrichments for lignocellulose degradation and reducing sugar production. A close examination of the mixed cultures revealed the presence of a large diversity of microbial morphotypes, generally including bacterial rods, cocci, and actinomycete-like cells. These microorganisms were embedded in an extracellular polymeric matrix. Most of the microorganisms grown in M1-CMC and M2-CMC were short rods and cocci; some long rod microbes were also found in M2-CMC, which was different from M1-CMC. In M1-LIG and M2-LIG cultures, cocci and filamentous microbes were embedded in the lignocellulose biomass. The microorganisms isolated from M1-FP were cocci and short rods, while those from M2-FP were curved rods and cocci.

DGGE analysis further indicated that approximately 7-12 dominant strains were present in the six enrichments (Fig. 2). A different medium or substrate results in a different dominant microbial population. Among the six combinations, M1-LIG and M2-LIG had relatively simpler microbial communities than the others feeding by CMC and FP. These lignocellulose-degrading-related bacteria were subsequently characterized by isolation.

\section{Isolation and phylogenetic analyses}

Seven bacterial strains were isolated from the obtained lignocellulose-degrading enrichments (Table 2). These 7 isolates were subjected to partial 16S rRNA gene sequencing for identification. The putative division and nearest relatives of these 7 isolates are summarized in Table 2 and Fig. 3.
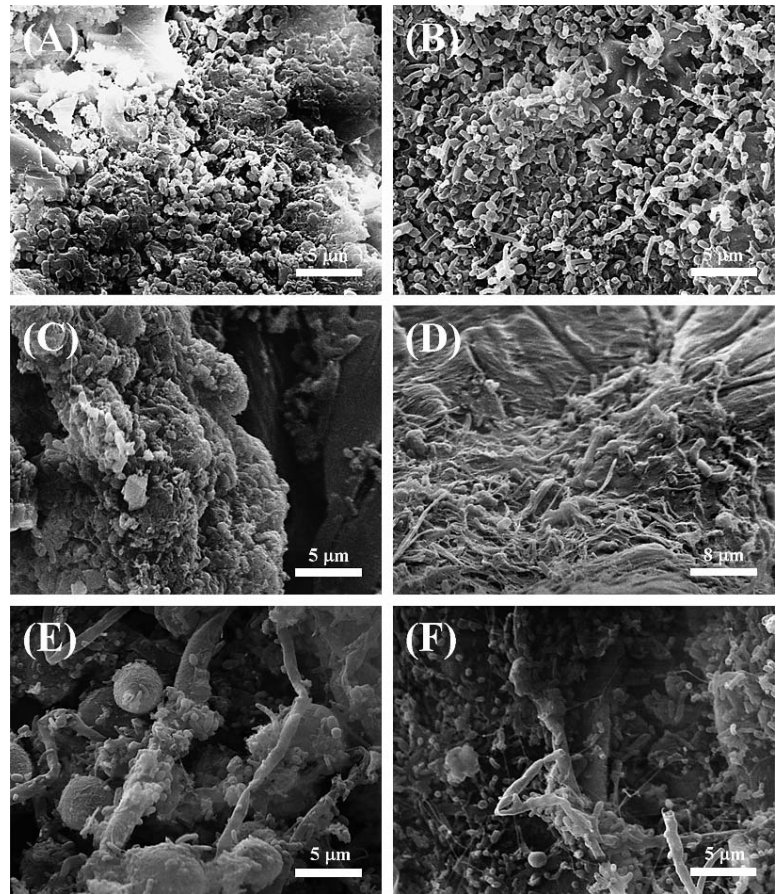

Fig. 1. Images of lignocellulose-degrading microorganisms by SEM from enrichments (A) M1-CMC, (B) M2-CMC, (C) M1-FP, (D) M2FP, (E) M1-LIG, and (F) M2-LIG. Scale bar indicates 5 or $8 \mu \mathrm{m}$.

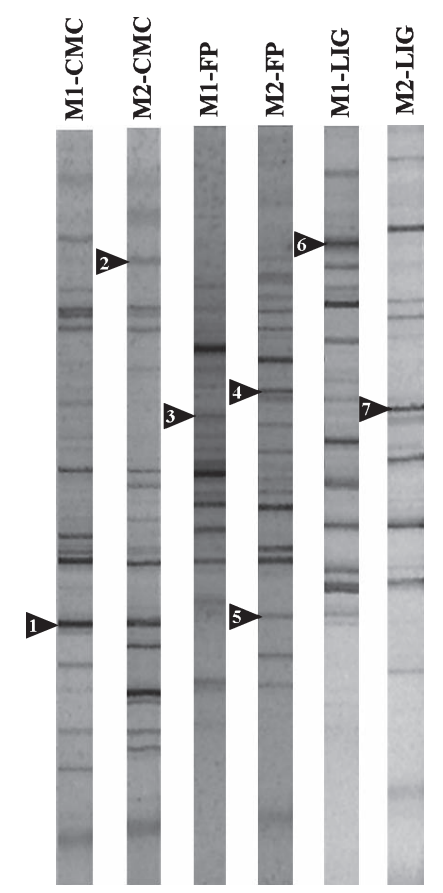

Fig. 2. Ethidium bromide-stained polyacrylamide denaturing gradient gel of 16S rRNA gene fragments. The source of each fingerprint is indicated above each lane. Arrows indicate the corresponding bacterial isolates on the gel (1: strain C42; 2: strain B18b; 3: strain B3a; 4: strain C12b; 5: strain C43a; 6: strain C26; 7: strain A10b).

From phylogenetic analyses, the isolated aerobic lignocellulolytic microorganisms belonged to various groups, including Actinobacteria (2 strains), Betaproteobacteria (1 strain) and Gammaproteobacteria (4 strains) (Table 2). The SEM observations (Fig. 1) were in line with the iden- 
Table 2. Taxonomic and phylogenetic characterization of isolates

\begin{tabular}{lllll}
\hline Isolates & \multicolumn{1}{c}{ Shape } & $\begin{array}{c}\text { Putative } \\
\text { division }\end{array}$ & $\begin{array}{c}\text { Accession } \\
\text { number }\end{array}$ & $\begin{array}{c}\text { Enrichment } \\
\text { sources }\end{array}$ \\
\hline C42 & Long rod & Actinobacteria & GU394958 & M1-CMC \\
C43a & Short rod & Actinobacteria & GU394959 & M2-FP \\
B18b & Short Rod & Protreobacteria & GU394953 & M2-CMC \\
C26 & Short rod & Protreobacteria & GU394954 & M1-LIG \\
C12b & Oval/cocci & Protreobacteria & GU394956 & M2-FP \\
A10b & Short rod & Protreobacteria & GU394957 & M2-LIG \\
B3a & Cocci & Protreobacteria & GU394955 & M1-FP \\
\hline
\end{tabular}

tification results and Bergey's Manual of Systematic Bacteriology (6). In Actinobacteria, the isolates (strains C42 and C43a) were affiliated with Agromyces sp., and Mycobacterium austroafricanum, respectively. In Betaproteobacteria, the isolate (strain $\mathrm{C} 12 \mathrm{~b}$ ) was closely related to Xenophilus azovorans. The rest of the isolates were affiliated with Strenotrophomonas spp. (strains A10b and B3a), and Pseudomonas spp. (strains B18b and C26) in Gammaproteobacteria. Additionally, these isolates corresponded to some of the major bands on the DGGE gel (Fig. 2); however, whether there are more yet-to-be-cultured bacteria from the DGGE gel that may be involved in lignocellulose degradation remains to be further explored.

\section{Microbial cocktail for effective and efficient degradation of lignocelluloses}

Four fast-growing strains among the obtained isolates, consisting of Agromyces sp. C42, Mycobacterium sp. C43a, Strenotrophomonas sp. A10b, and Pseudomonas sp. C26,
Table 3. Reducing sugar production from lignocelluloses by the identified microbial strains

\begin{tabular}{lcc}
\hline \multirow{2}{*}{ Bacterial strains } & \multicolumn{2}{c}{ Reducing sugars $\left(\mathrm{mg} \mathrm{g}-\mathrm{LIG}^{-1}\right)$} \\
\cline { 2 - 3 } & \multicolumn{1}{c}{$24 \mathrm{~h}$} & $48 \mathrm{~h}$ \\
\hline $\mathrm{C} 42$ & $10.8 \pm 1.0$ & $12.1 \pm 1.0$ \\
$\mathrm{C} 43 \mathrm{a}$ & $13.2 \pm 1.0$ & $30.2 \pm 0.9$ \\
$\mathrm{~A} 10 \mathrm{~b}$ & $0.5 \pm 0.1$ & $0.7 \pm 0.1$ \\
$\mathrm{C} 26$ & $9.5 \pm 1.1$ & $9.8 \pm 1.4$ \\
$\mathrm{C} 42+\mathrm{C} 43 \mathrm{a}$ & $21.8 \pm 1.8$ & $52.3 \pm 1.1$ \\
$\mathrm{C} 42+\mathrm{A} 10 \mathrm{~b}$ & $35.8 \pm 2.3$ & $56.7 \pm 2.0$ \\
$\mathrm{C} 42+\mathrm{C} 26$ & $12.3 \pm 1.7$ & $41.2 \pm 1.2$ \\
$\mathrm{~A} 10 \mathrm{~b}+\mathrm{C} 26$ & $11.8 \pm 1.2$ & $3.3 \pm 1.0$ \\
C42+C43a+A10b & $5.3 \pm 0.9$ & $3.3 \pm 1.2$ \\
C42+C43a+C26 & $17.0 \pm 1.0$ & $6.9 \pm 0.9$ \\
C42+A10b+C26 & $6.9 \pm 1.2$ & $4.0 \pm 1.0$ \\
C43a+A10b+C26 & $11.0 \pm 1.0$ & $27.4 \pm 1.2$ \\
C42+C43a+A10b+C26 & $<0.1$ & $<0.1$ \\
\hline
\end{tabular}

were selected to investigate the best defined microbial cocktail which can effectively convert lignocellulosic waste to reducing sugars. A series of combination tests was carried out using two to four strains. Table 3 shows the summary of reducing sugar production from lignocellulose by individual strains and microbial cocktails within $48 \mathrm{~h}$. All the original strains had reducing sugar production at 12.1 (strain C42), 30.2 (strain C43a), 0.7 (strain A10b) and $9.8 \mathrm{mg}$ g-LIG ${ }^{-1}$ (strain C26) within 48-h incubation. The reducing sugar production of Strenotrophomonas sp. A10b was only observed after 96-h incubation (data not shown). For microbial cocktails, four combinations (i.e., $\mathrm{C} 42+\mathrm{A} 10 \mathrm{~b}$,

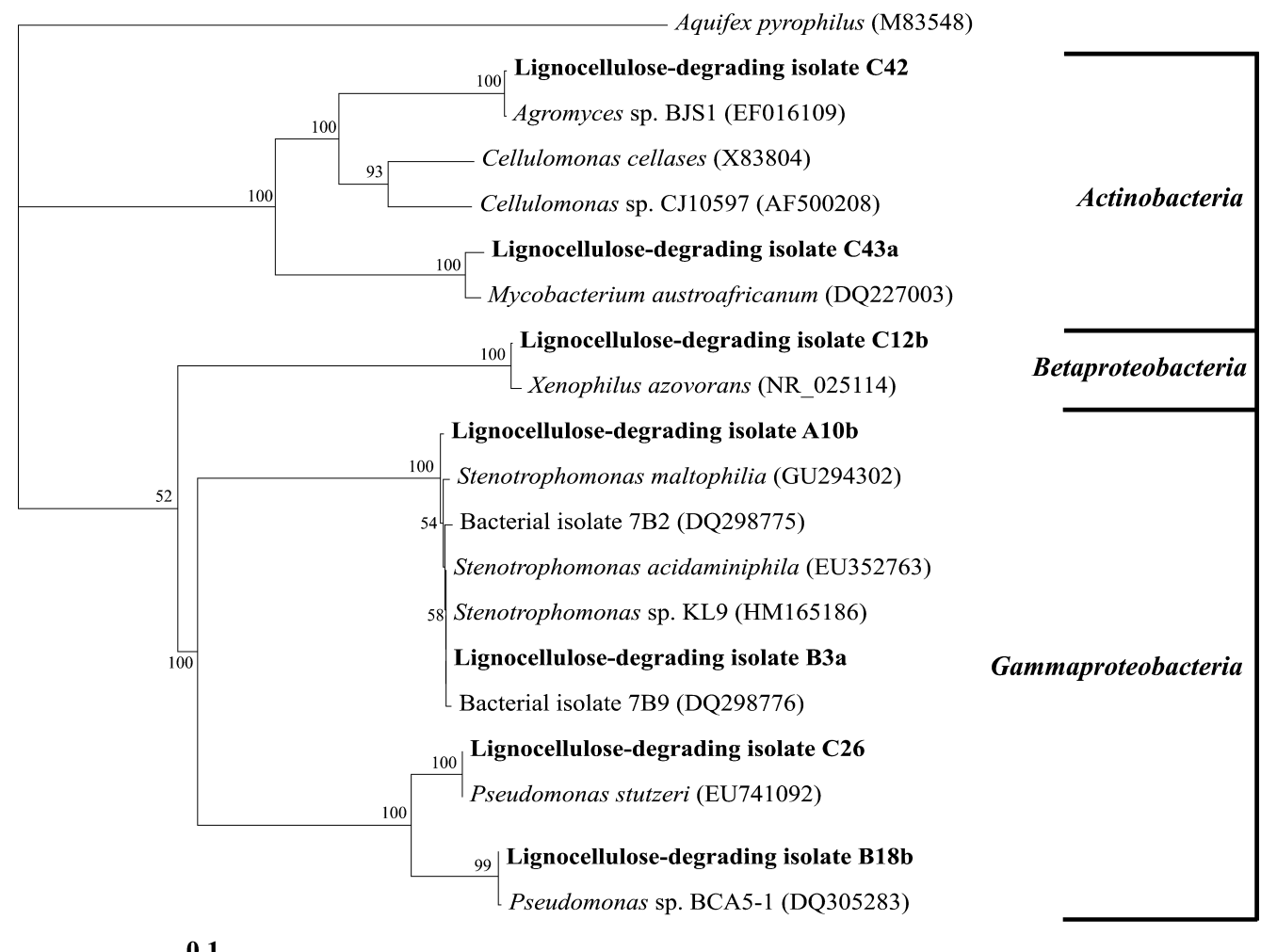

Fig. 3. Phylogenetic tree of $16 \mathrm{~S}$ rRNA gene sequences $(>1,300 \mathrm{bp})$ constructed for lignocellulose-degrading isolates from guts of yellow mealworm. The tree was obtained using the neighbor-joining algorithm with bootstrapping (PHYLIP). Aquifex pyrophilus (M83548) was used as the outgroup. Scale bar represents the estimated number of nucleotide changes per sequence position. 
$\mathrm{C} 42+\mathrm{C} 43 \mathrm{a}, \mathrm{C} 42+\mathrm{C} 26, \mathrm{C} 43 \mathrm{a}+\mathrm{A} 10 \mathrm{~b}+\mathrm{C} 26)$ showed a higher production of reducing sugars than individual strains, ranging from 27.4 to $56.7 \mathrm{mg}$ g- $\mathrm{LIG}^{-1}$. Among these combinations, the best microbial cocktail consisting of Agromyces sp. C42 and Strenotrophomonas sp. A10b was identified. The reducing sugar yield of this microbial cocktail was $56.7 \mathrm{mg} \mathrm{g}-\mathrm{LIG}^{-1}$, which is approximately $2-5$ times higher than the original combinations from the enrichments (Table 1) and individual strains (Table 3).

\section{Discussion}

Lignocellulosic waste has been widely treated as identical to other solid wastes by incineration or composting, and the value of these organic wastes has been overlooked for a long time. Cellulose and hemicellulose from lignocellulosic waste have been reported to be degraded to reducing sugars for fuel or useful chemical production (e.g., ethanol) by microorganisms (1). Bioconversion by microorganism offers a cheaper and safer method than chemical treatments. In this study, after 6 months of sequential cultivation and selection, lignocellulose-degrading microbial communities were successfully established from the guts of yellow mealworm using 2 basic nutrients (M1 and M2) with three carbon sources (i.e., CMC, FP and LIG). All six microbial communities reached a steady state of lignocellulose degradation under aerobic conditions. Kato and co-workers (8) reported that stable cellulose degradation efficiency was $83 \%$ aerobically and only $19.3 \%$ anaerobically (for 8 days) respectively. The other two studies $(1,32)$ also suggested a long degradation time (15-30\% lignocellulose degradation aerobically for 25 days, whereas 250 days of incubation was required under anaerobic conditions). Our findings not only support the high degradation rates of lignocelluloses under aerobic conditions, but also further demonstrate that very high efficiency can be achieved within $48 \mathrm{~h}$ (47.5-73.3\%, Table 1).

Seven bacterial strains were successfully isolated corresponding to some of the major bands detected by DGGE analysis from the enriched microflora after 6-month cultivation. Among the obtained isolates, strains A10b and B3a, which are closely related to Stenotrophomonas in Gammaproteobacteria, have been suggested to have high lignocellulose degradability (8). Another two strains (B18b and C26) in Gammaproteobacteria were affiliated with members of the Pseudomonas, which are reportedly strict aerobes and commonly known for the presence of various metabolic pathways that are capable of degrading complex organic compounds, including xenobiotics (11). In the Actinobacteria group, one strain C42, related to Agromyces and Cellulomonas, was obtained, which has been described as coryneform bacteria that produce at least six endoglucanases and one exoglucanase (Cex) with cellulose-degrading ability (2). Various strains of Cellulomonas have been reported to have high utilization on cellulosic substrates and low utilization on xylan, galactomannan, starch and sugars (21).

The best combination of microbial cocktail consisting of Agromyces sp. C42 and Stenotrophomonas sp. A10b was successfully constructed in this study, and could produce 56.7 $\mathrm{mg}$ reducing sugar per $1 \mathrm{~g} \mathrm{LIG}$ (Table 3). Agromyces sp. C42 could play a positive role in the combination; one strain of this species was isolated in a Chinese primeval forest (13) and was also found to degrade torrefied grass fibers (28). Stenotrophomonas sp. A10b showed low reducing sugarproducing capability on its own, and it has not been reported to relate to lignocellulose degradation; however, when it was combined with Agromyces sp. C42, this combination obtained the maximum reducing sugar yield in this study. The function of Agromyces-related bacteria during lignocellulose degradation and reducing sugar production is unclear. Another interesting finding during combination was that no reducing sugar was detected when these four isolates were combined.

The other remarkable combination of microbial cocktail was Agromyces sp. C42 and Mycobacterium sp. C43a, which could produce $52.3 \mathrm{mg}$ reducing sugar per $1 \mathrm{~g}$ LIG. Mycobacterium sp. C43a shows good coexistence in combination, and is an aerobic actinomycete and a fungi-like bacterium (31). Actinomycete is known for its ability to degrade both lignin and cellulose in lignocelluloses that are commonly found in soil (20). These defined microbial combinations are significant for reducing sugar production from lignocellulosic waste and suggest that a synthetic cocktail is much better than the original microbial communities and single strains. The selected species and combinations are unique and have been seldom reported from this aspect.

\section{Conclusion}

In conclusion, polysaccharides (i.e., cellulose and hemicellulose) in lignocellulosic waste can be degraded by microorganisms from the guts of yellow mealworm under aerobic conditions. Seven bacterial strains were successfully isolated in this study. A microbial cocktail (Agromyces sp. $\mathrm{C} 42$ and Stenotrophomonas sp. A10b) was successfully constructed with 2-5 times more reducing sugar yield than the original combination and individual isolated strains. Although this microbial cocktail showed good lignocellulosedegrading activity, the reducing sugar conversion rate was only $5.7 \%(\mathrm{w} / \mathrm{w})$, suggesting that potential applications in the future should focus on lignocellulosic waste minimization. Furthermore, the active functional genes and the interaction among microorganisms in the microbial cocktail remain to be further investigated.

\section{References}

1. Benner, R., and R.E. Hodson. 1985. Microbial degradation of the leachable and lignocellulosic components of leaves and wood from Rhizophora mangle in a tropical mangrove swamp. Mar. Ecol. Prog. Ser. 23:221-230.

2. Chaudhary, P., N.N. Kumar, and D.N. Deobagkar. 1997. The glucanases of Cellulomonas. Biotehnol. Adv. 15:315-331.

3. Das, M., T.V. Royer, and L.G. Leff. 2007. Diversity of fungi, bacteria, and actinomycetes on leaves decomposing in a stream. Appl. Environ. Microbiol. 73:756-767.

4. DuBois, M., K.A. Gilles, J.K. Hamilton, P.A. Rebers, and F. Smith. 1956. Colorimetric method for determination of sugars and related substances. Anal. Biochem. 28:350-356.

5. Ferreira, A.H.P., P.T. Cristofoletti, D.M. Lorenzini, L.O. Guerra, P.B. Paiva, M.R.S. Briones, W.R. Terra, and C. Ferreira. 2007. Identification of midgut microvillar proteins from Tenebrio molitor and Spodoptera frugiperda by cDNA library screenings with antibodies. J. Insect Physiol. 53:1112-1124. 
6. Garrity, G.M.B., D.R. Boone, and R.W. Castenholz. 2001. Bergey's Manual of Systematic Bacteriology. Second edition. Williams \& Wilkins, New York, USA.

7. Jimenez, L., and J.L. Bonilla. 1993. Acid hydrolysis of sunflower residue biomass. Process Biochem. 28:243-247.

8. Kato, S., S. Haruta, Z.J. Cui, M. Ishii, and Y. Igarashi. 2004. Effective cellulose degradation by a mixed-culture system composed of a cellulolytic Clostridium and aerobic non-cellulolytic bacteria. FEMS Microbiol. Ecol. 51:133-142.

9. Kim, J.-S. 1999. Application of DGGE analysis to the study of bacterial community structure in plant roots and in nonrhizosphere soil Soil Sci. Plant Nutr. 45:493-497.

10. Koukiekolo, R., H.-Y. Cho, A. Kosugi, M. Inui, H. Yukawa, and R.H. Doi. 2005. Degradation of corn fiber by clostridium cellulovorans cellulases and hemicellulases and contribution of scaffolding protein CbpA. Appl. Environ. Microbiol. 71:3504-3511.

11. Landy, E.T., J.I. Mitchell, S. Hotchkiss, and R.A. Eaton. 2008. Bacterial diversity associated with archaeological waterlogged wood: Ribosomal RNA clone libraries and denaturing gradient gel electrophoresis (DGGE). Int. Biodeterior. Biodegrad. 61:106-116.

12. Lewis, S.M., L. Montgomery, K.A. Garleb, L.L. Berger, and G.C. Fahey, Jr. 1988. Effects of alkaline hydrogen peroxide treatment on in vitro degradation of cellulosic substrates by mixed ruminal microorganisms and Bacteroides succinogenes S85. Appl. Environ. Microbiol. 54:1163-1169.

13. Li, W.-J., L.-P. Zhang, P. Xu, X.-L. Cui, L.-H. Xu, Z. Zhang, P. Schumann, E. Stackebrandt, and C.-L. Jiang. 2003. Agromyces aurantiacus sp. nov., isolated from a Chinese primeval forest. Int. J. Syst. Evol. Microbiol. 53:303-307.

14. Miller, G.L. 1959. Use of Dinitrosalicylic acid reagent for determination of reducing sugar. Anal. Biochem. 31:426-428.

15. Miura, H., M. Horiguchi, K. Ogimoto, and T. Matsumoto. 1983. Nutritional interdependence among rumen bacteria during cellulose digestion in vitro. Appl. Environ. Microbiol. 45:726-729.

16. Muyzer, G., E.C. de Waal, and A.G. Uitterlinden. 1993. Profiling of complex microbial populations by denaturing gradient gel electrophoresis analysis of polymerase chain reaction-amplified genes coding for 16S rRNA. Appl. Environ. Microbiol. 59:695-700.

17. Nguyen, Q.A., M.P. Tucker, F.A. Keller, D.A. Beaty, K.M. Connors, and F.P. Eddy. 1999. Dilute acid hydrolysis of softwoods. Appl. Biochem. Biotechnol. 77:133-142.

18. Pan, J., S. Koike, T. Suzuki, K. Ueda, Y. Kobayashi, K. Tanaka, and M. Okubo. 2003. Effect of mastication on degradation of orchardgrass hay stem by rumen microbes: fibrolytic enzyme activities and microbial attachment. Anim. Feed Sci. Technol. 106:69-79.

19. Parajó, J.C., H. Dominguez, and J.M. Domínguez. 1997. Improved xylitol production with Debaryomyces hansenii Y-7426 from raw or detoxified wood hydrolysates. Enzyme Microb. Technol. 21:18-24.
20. Pasti, M.B., A.L. Pometto, 3rd, M.P. Nuti, and D.L. Crawford. 1990. Lignin-solubilizing ability of actinomycetes isolated from termite (Termitidae) gut. Appl. Environ. Microbiol. 56:2213-2218.

21. Poulsen, O.M., and L.W. Petersen. 1988. Growth of Cellulomonas sp. ATCC 21399 on different polysaccharides as sole carbon source Induction of extracellular enzymes. Appl. Microbiol. Biotechnol. 29:480-484.

22. Saha, B.C., L.B. Iten, M.A. Cotta, and Y.V. Wu. 2005. Dilute acid pretreatment, enzymatic saccharification and fermentation of wheat straw to ethanol. Process Biochem. 40:3693-3700.

23. Soccol, C.R., B. Marin, M. Raimbault, and J.M. Lebeault. 1994. Potential of solid state fermentation for production of $\mathrm{L}(+)$-lactic acid by Rhizopus oryzae. Appl. Microbiol. Biotechnol. 41:286-290.

24. Sun, J.X., X.F. Sun, R.C. Sun, and Y.Q. Su. 2004. Fractional extraction and structural characterization of sugarcane bagasse hemicelluloses. Carbohydr. Polym. 56:195-204.

25. Sun, Y., and J.J. Cheng. 2005. Dilute acid pretreatment of rye straw and bermudagrass for ethanol production. Bioresour. Technol. 96:1599-1606.

26. Terra, W.R., C. Ferreira, and F. Bastos. 1985. Phylogenetic considerations of insect digestion: Disaccharidases and the spatial organization of digestion in the Tenebrio molitor larvae. Insect Biochem. 15:443-449.

27. Terra, W.R., and C. Ferreira. 1994. Insect digestive enzymes: properties, compartmentalization and function. Comp. Biochem. Physiol., Part B: Biochem. Mol. Biol. 109:1-62.

28. Trifonova, R., J. Postma, M. Schilder, and J. van Elsas. 2009. Microbial enrichment of a novel growing substrate and its effect on plant growth. Microb. Ecol. 58:632-641.

29. Weisburg, W.G., S.M. Barns, D.A. Pelletier, and D.J. Lane. 1991. $16 \mathrm{~S}$ ribosomal DNA amplification for phylogenetic study. J. Bacteriol. 173:697-703.

30. Wenzel, M., I. Schonig, M. Berchtold, P. Kampfer, and H. Konig. 2002. Aerobic and facultatively anaerobic cellulolytic bacteria from the gut of the termite Zootermopsis angusticollis. J. Appl. Microbiol. 92:32-40.

31. Weon, H.-Y., S.-H. Yoo, R. Anandham, P. Schumann, R.M. Kroppenstedt, S.-W. Kwon, and E. Stackebrandt. 2010. Tsukamurella soli sp. nov., isolated from soil. Int. J. Syst. Evol. Microbiol. 60:1667-1671.

32. Yang, S.-J., I. Kataeva, S.D. Hamilton-Brehm, N.L. Engle, T.J. Tschaplinski, C. Doeppke, M. Davis, J. Westpheling, and M.W.W. Adams. 2009. Efficient degradation of lignocellulosic plant biomass, without pretreatment, by the thermophilic anaerobe "Anaerocellum thermophilum” DSM 6725. Appl. Environ. Microbiol. 75:4762-4769. 